\title{
Upregulation of IL-1 Receptor Antagonist in a Mouse Model of Migraine
}

\author{
Salvo Danilo Lombardo ${ }^{1}$, , Emanuela Mazzon ${ }^{2}$, Maria Sofia Basile ${ }^{1}$, Eugenio Cavalli ${ }^{2}$, \\ Placido Bramanti ${ }^{2}$, Riccardo Nania ${ }^{1}$, Paolo Fagone ${ }^{1}\left(\mathbb{D}\right.$, Ferdinando Nicoletti ${ }^{1} * \mathbb{D}$ and \\ Maria Cristina Petralia ${ }^{2}$ \\ 1 Department of Biomedical and Biotechnological Sciences, University of Catania, Via S. Sofia 89, \\ 95123 Catania, Italy \\ 2 IRCCS Centro Neurolesi Bonino Pulejo, Strada Statale 113, C.da Casazza, 98124 Messina, Italy \\ * Correspondence: ferdinic@unict.it; Tel.: +39-095-478-1270
}

Received: 9 July 2019; Accepted: 18 July 2019; Published: 19 July 2019

check for updates

\begin{abstract}
Migraine is a disorder characterized by attacks of monolateral headaches, often accompanied by nausea, vomiting, and photophobia. Around 30\% of patients also report aura symptoms. The cause of the aura is believed to be related to the cortical spreading depression (CSD), a wave of neuronal and glial depolarization originating in the occipital cortex, followed by temporary neuronal silencing. During a migraine attack, increased expression of inflammatory mediators, along with a decrease in the expression of anti-inflammatory genes, have been observed. The aim of this study was to evaluate the expression of inflammatory genes, in particular that of IL-1 receptor antagonist (IL-1RN), following CSD in a mouse model of familial hemiplegic migraine type 1 (FHM-1). We show here that the expression of $I L-1 R N$ was upregulated after the CSD, suggesting a possible attempt to modulate the inflammatory response. This study allows researchers to better understand the development of the disease and aids in the search for new therapeutic strategies in migraine.
\end{abstract}

Keywords: migraine; IL-1RN; cortical spreading depression; mouse model

\section{Introduction}

Migraine is a common neurological disease, representing the fourth cause of years lived with disability (YLDs) for women, and the eighth for men [1-3]. It is characterized by attacks of monolateral headaches, associated with nausea as well as phono- and photophobia [4]. Around 30\% of patients also report aura symptoms, which are mostly visual. The cause of the aura is believed to be related to the cortical spreading depression (CSD), a self-propagating wave of cellular depolarization from the occipital cortex, followed by a transitory neuronal silencing $[5,6]$.

The manifestation of these attacks depends on a genetic predisposition, associated to environmental stimuli such as stress, hormones, meteorological changes, and sleep disorders. For this reason, it is difficult to identify the etiology and physiopathogenesis of migraine. Recent evidence also suggests that immunoinflammatory events may also play a role in the pathogenesis of migraine $[7,8]$.

In particular, much attention has been given to the role of immune-system hormones, named cytokines, to the pathogenesis of migraine [9].

Based on preclinical and clinical studies, the cytokines have been divided into at least five subfamilies: the proinflammatory Th1/Th17 cytokines, the anti-inflammatory Th2/Th3 cytokines, and the Th9 cytokine, represented by IL-9 [10-12].

It has been shown that Th1 and Th17 cytokines primarily exert proinflammatory effects. They are produced by M1 macrophages, Th1 and Th17 cells, and include-among others-IL-1, TNF-alpha, IFN-gamma, IL-12, IL-18, IL-22, IL-23, and IL-17. They may contribute to the initiation of 
cell-mediated autoimmune diseases such as rheumatoid arthritis, type 1 diabetes, multiple sclerosis, and Guillain-Barré syndrome [10,11,13].

Anti-inflammatory cytokines (e.g., IL-4, IL-10, IL-13 IL-35, TGF-beta) are primarily produced from M2 macrophages and Th2 and Th3 cells. They decrease Th1- and Th17-mediated immunoinflammatory events, and are implicated in IgE-mediated allergic diseases and eosinophil-mediated pathologies [14-17].

Sometimes, such as in the case of systemic lupus erythematosus, it seems that the combined action of Th1/Th2 cytokines may be simultaneously involved in the pathogenesis of the disease [18]. The precise role of IL-9 in regulation of the immune responses is less well-defined, and is receiving a great deal of attention [12].

In addition, the function of cytokines is also finely regulated by endogenous antagonists, which have been described for most cytokines, such as soluble receptors, anti-cytokine autoantibody, and for IL-1, the IL-1 receptor antagonist [19-21]. These endogenous antagonists are usually produced during immune responses, and serve to control and downregulate excessive signaling of the cytokine through binding with its functionally active receptors expressed on the surface of the target cells. For example, we have shown that blood levels of IL-1ra are augmented during attacks of multiple sclerosis and are further augmented from the treatment of the patients with IFN-beta [22].

Cytokines have recently been associated to the etiology of migraine, even if conflicting results have been found [23-25]. The association between migraine and the interleukin-1 receptor antagonist variable number tandem repeat (IL-1RN VNTR) has previously been investigated, but no statistically significant differences were discovered [26].

A cross-talk between neurons and immune cells has also been reported, which may contribute to the generation of the pain [27]. Indeed, activated macrophages and other non-neuronal cells might induce a meningeal "sterile inflammation" [28,29], contributing to the pain symptoms [30,31]. Furthermore, it has been reported that inflammation in the trigeminal nerve territory is often observed during migraine attacks [32], so the acute administration of corticosteroids has been tested to block pain [33].

Familial hemiplegic migraine type 1 (FHM-1) is a monogenic type of migraine with aura caused by mutations in the CACNA1A gene which determine an alteration of the passage of $\mathrm{Ca}^{2+}$ ions in the cerebral cortex $[34,35]$. The FHM mouse model, generated by introducing the R192Q mutation into the endogenous CACNA1A gene [36], is used to study the physiopathology of FHM-1 [37,38]. R192Q KI mice have increased neuronal $\mathrm{Ca}^{2+}$ influx and augmented glutamate release [39], which may explain the increased susceptibility to CSD [36,39]. Data from animal models have shown that CSD is able to activate meningeal trigeminovascular neurons, generating the sensation of pain [40-42].

The aim of the present study was to determine the expression of inflammatory genes and in particular that of IL-1 receptor antagonist $(I L-1 R N)$ upon CSD, in a murine model of FHM1.

\section{Materials and Methods}

\subsection{Dataset Selection and Analysis}

In order to evaluate the brain expression levels of $I L-1 R N$ following CSD, we interrogated the GSE67933 dataset, obtained from the GEO dataset [43]. The dataset included whole-genome transcriptomic data from wild-type (WT) mice and transgenic mice carrying the CACNA1A R192Q missense mutation (FHM1 R192Q mice). Gene expression profiles were obtained from cortical tissue of FHM1 R192Q and control mice, $24 \mathrm{~h}$ after experimentally induced CSD [44]. Briefly, CSD was induced by seven applications of a cotton pellet soaked in $300 \mathrm{mM} \mathrm{KCl}$ on the dura overlaying the occipital cortex, while in sham animals $300 \mathrm{mM} \mathrm{NaCl}$ was applied instead of $\mathrm{KCl}$ [44]. Deep SAGE sequencing was used to generate the expression profiles, and the data were normalized using the trimmed mean of M-values (TMM) method.

Functionally correlated genes were obtained using the web-based software STRING [45] and visualized as a gene network. Relationships of genes in the network were defined in terms of co-expression, text-mining, biochemical data, curated pathway, and protein-protein interactions. 
The confidence cut-off for showing interaction links was set as medium (0.4) and the maximum number of interactors in the first shell was set at 50 .

Heatmapper [46] software was used to generate the expression heatmap of the functional related genes to $I L-1 R N$ and to perform hierarchical clustering of genes. Average linkage was used as clustering method and Euclidean distance as distance measurement.

Co-expression analysis was carried out using the CoExpress software [47], and gene enrichment for biological processes (BPs) and molecular functions (MFs) was performed using the web-based utility DAVID version 6.8 [48].

\subsection{Statistical Analysis}

Data are shown as mean \pm standard deviation. Differences in $I L-1 R N$ expression among the experimental groups were evaluated by ANOVA (Student's $t$-test) with Bonferroni post-hoc test. Correlation analysis was performed using the Pearson's correlation test. Statistical analysis was performed using IBM SPSS Statistics 23 [49] and GraphPad Prism 8.0.2 [50].

\section{Results}

\subsection{IL-1RN Expression after CSD}

The GSE67933 dataset was used to determine the expression levels of IL-1RN following CSD in a murine model of FHM1 (Figure 1). No significant differences in IL-1RN levels were observed in FHM1 R192Q vs. wild-type (WT) cortex at basal condition (sham). No significant differences in IL-1RN expression were observed following CSD induction in WT mice as compared to sham-operated WT mice. Significantly higher levels of IL-1RN were observed upon CSD in FHM1 R192Q animals as compared to sham-operated mice $(p<0.0001)$ (Figure 1$)$.

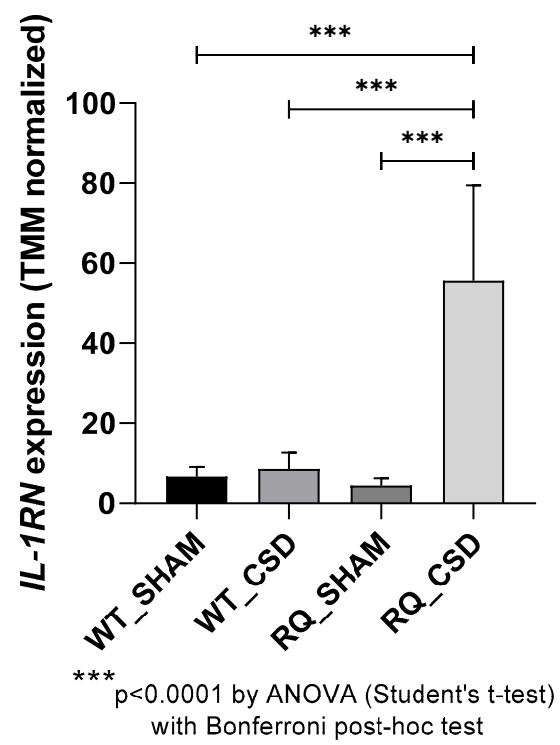

Figure 1. $I L-1 R N$ expression in a model of migraine. The expression of $I L-1 R N$ was investigated in mice bearing the R192Q mutation and wild-type (WT) mice at baseline and following CSD, as determined in the GSE67933 dataset. Data are presented as trimmed mean of M-values (TMM) normalized expression.

\subsection{Identification of Genes Functionally Related to IL-1RN}

We then evaluated the expression of the genes functionally related to $I L-1 R N$ (Figure 2A and Supplementary File 1). As shown in Figure 2 and Table 1, several of the genes identified were found to be modulated in the cortex from FHM1 R192Q mice subjected to CSD (Figure 2B). Among them, a significant upregulation of $I L-6, T N F, T L R 2$, and TLR4 could be observed in FHM1 R192Q mice upon CSD as compared to FHM1 R192Q sham-operated mice (Supplementary Table S1). Moreover, as 
compared to CSD-induced WT mice, FHM1 R192Q mice upon CSD expressed lower levels of $I L-18$, $I L-10, I L-2, I L-4$, and $I L-13$, and significantly higher levels of IFNK, IL-17A, SOCS3, and of several members of the chemokine/chemokine receptor family (CCL2, CXCL2, CXCL10, CCL4, CCL7, CXCL1, CXCL3, CCR1, CXCL9).
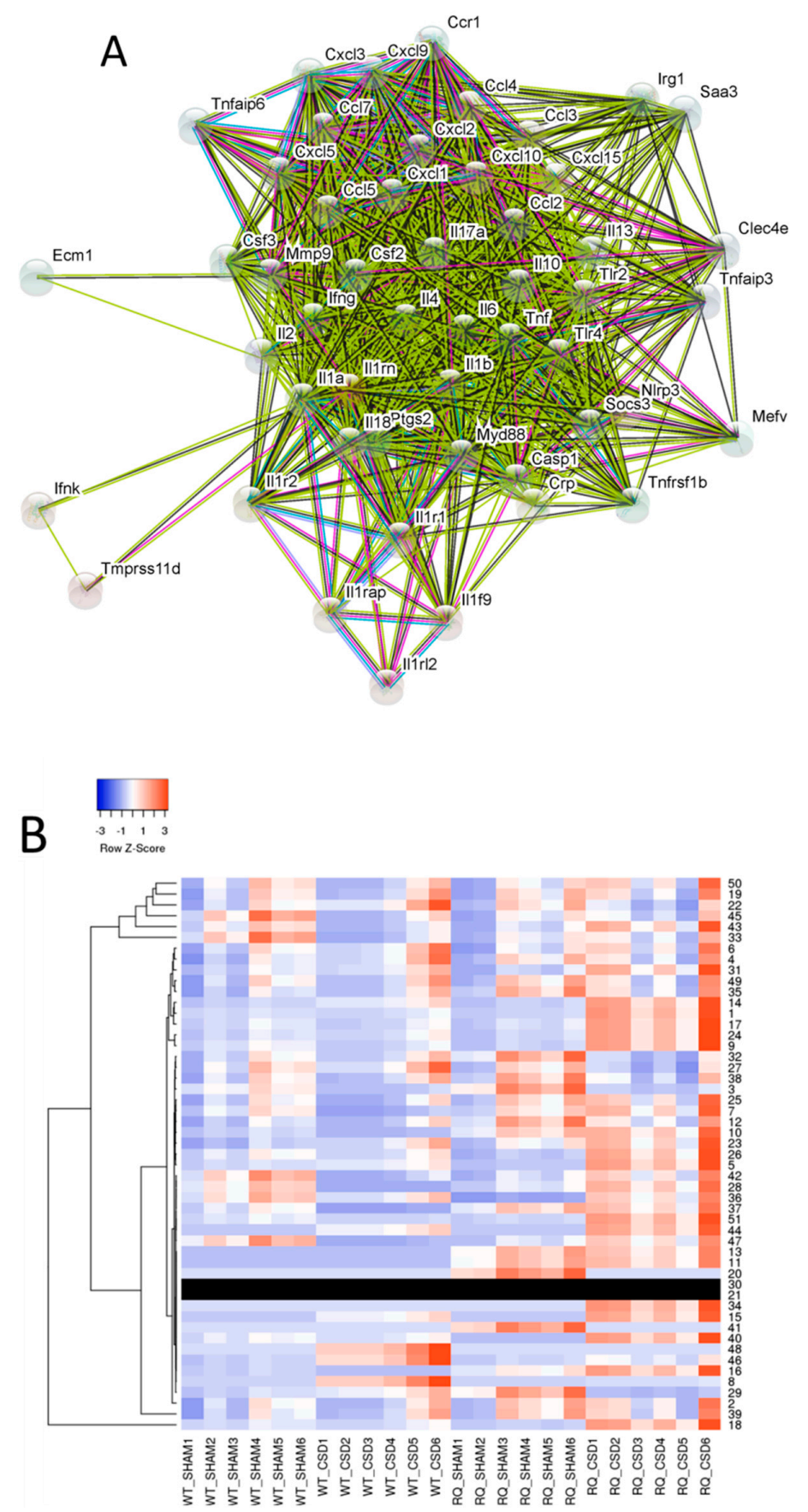

Figure 2. $I L-1 R N$ functionally-related genes. (A) Gene network of the $I L-1 R N$ functionally related genes. The edges connecting the nodes represent the interactions between genes, in terms of co-expression (black), text mining (light green), protein homology (cyan), association in curated database (light blue), and high-throughput experiments (purple). Empty nodes represent proteins of uncharacterized 3D structure, while filled nodes represent proteins with known or predicted tertiary structure. (B) Expression heatmap for the top correlated genes to IL-1RN, as determined in the GSE67933 dataset. Average linkage was used as clustering method and Euclidean distance as distance measurement. Tree branches represent the distance between genes. 


\subsection{Identification of Genes Statistically Correlated to IL-1RN}

We found 927 genes statistically correlated to IL-1RN in CDS-induced FHM1 R192Q mice, considering as threshold a Pearson correlation coefficient $(\mathrm{r})>0.95$ and a $p$-value $<0.05$. The top 20 statistically significant correlated genes are presented in Table 1. Gene Ontology for biological processes (BPs) revealed a significant enrichment of genes involved in the "G-protein coupled receptor signaling pathway" $(p<0.0001)$, "sensory perception of smell" $(p<0.0001)$ and "inflammatory response" $(p<0.0001)$ (Figure 3A). The top enriched molecular functions (MFs) were: "olfactory receptor activity" $(p<0.0001)$, G-protein coupled receptor activity $(p<0.0001)$ and "odorant binding" $(p<0.0001)$ (Figure 3B).
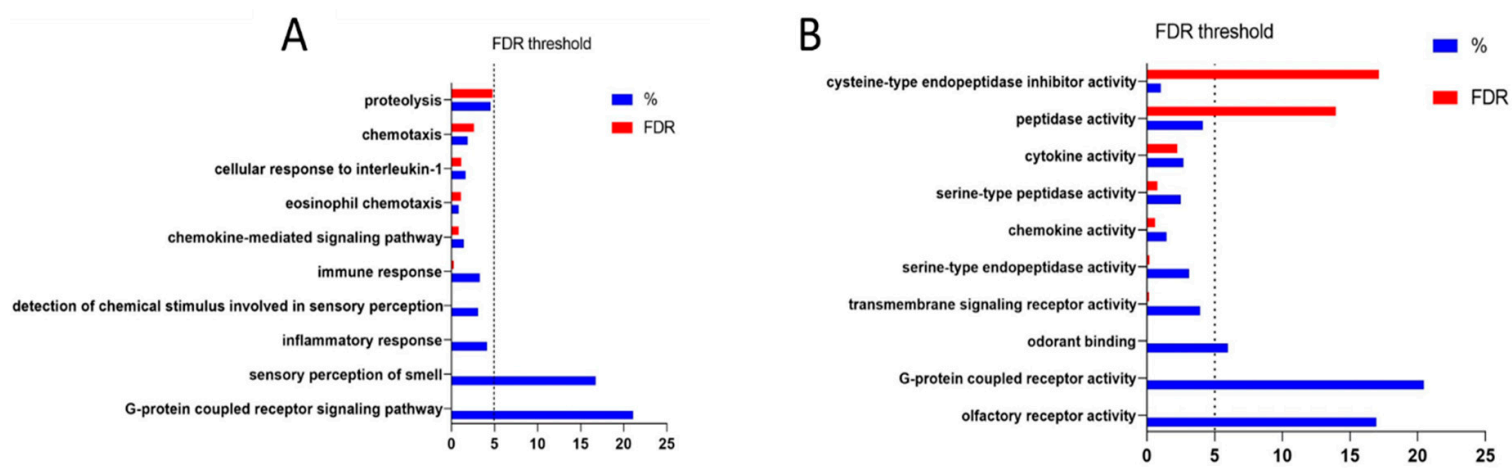

Figure 3. Gene ontology analysis for the genes statistically correlated to IL-1RN in the model of cortical spreading depression (CSD)-induced migraine. (A) Most enriched biological processes; (B) Most enriched molecular functions. FDR: False Discovery Rate

Table 1. Top 20 genes statistically correlated to $I L-1 R N$.

\begin{tabular}{clcccc}
\hline Gene & Gene Stable ID & Pearson r & $\begin{array}{c}\text { 95\% Confidence } \\
\text { Interval }\end{array}$ & $\boldsymbol{p}$-Value & $\boldsymbol{R}$ Squared \\
\hline Cdhr5 & ENSMUSG00000025497 & 0.9996 & 0.9991 to 0.9998 & $<0.0001$ & 0.9992 \\
Gm8251 & ENSMUSG00000091844 & 0.9996 & 0.9991 to 0.9998 & $<0.0001$ & 0.9993 \\
Scarna3b & ENSMUSG00000088158 & 0.9993 & 0.9983 to 0.9997 & $<0.0001$ & 0.9986 \\
Nr0b1 & ENSMUSG00000025056 & 0.9991 & 0.9980 to 0.9996 & $<0.0001$ & 0.9983 \\
Lrrc15 & ENSMUSG00000052316 & 0.9987 & 0.9968 to 0.9994 & $<0.0001$ & 0.9973 \\
Ifi204 & ENSMUSG00000073489 & 0.9982 & 0.9959 to 0.9993 & $<0.0001$ & 0.9965 \\
Cd200r3 & ENSMUSG00000036172 & 0.9981 & 0.9955 to 0.9992 & $<0.0001$ & 0.9962 \\
Gm13389 & ENSMUSG00000087079 & 0.9977 & 0.9947 to 0.9990 & $<0.0001$ & 0.9955 \\
Hpx & ENSMUSG00000030895 & 0.9976 & 0.9944 to 0.9990 & $<0.0001$ & 0.9953 \\
Gm15941 & ENSMUSG00000086992 & 0.9974 & 0.9940 to 0.9989 & $<0.0001$ & 0.9949 \\
Zc3h12d & ENSMUSG00000039981 & 0.9973 & 0.9938 to 0.9989 & $<0.0001$ & 0.9947 \\
Gm49339 & ENSMUSG00000062593 & 0.9973 & 0.9936 to 0.9988 & $<0.0001$ & 0.9945 \\
Klre1 & ENSMUSG00000050241 & 0.9971 & 0.9933 to 0.9988 & $<0.0001$ & 0.9943 \\
Klk9 & ENSMUSG00000047884 & 0.9966 & 0.9921 to 0.9986 & $<0.0001$ & 0.9933 \\
Gm22486 & ENSMUSG00000080465 & 0.9966 & 0.9921 to 0.9986 & $<0.0001$ & 0.9933 \\
Abo & ENSMUSG00000015787 & 0.9965 & 0.9919 to 0.9985 & $<0.0001$ & 0.9931 \\
Cnga3 & ENSMUSG00000026114 & 0.9965 & 0.9917 to 0.9985 & $<0.0001$ & 0.9929 \\
Ccl4 & ENSMUSG00000018930 & 0.9960 & 0.9906 to 0.9983 & $<0.0001$ & 0.9920 \\
Snord66 & ENSMUSG00000077239 & 0.9958 & 0.9901 to 0.9982 & $<0.0001$ & 0.9916 \\
Gm13429 & ENSMUSG00000085141 & 0.9957 & 0.9898 to 0.9982 & $<0.0001$ & 0.9913 \\
\hline
\end{tabular}

\section{Discussion}

Many studies have shown a relationship between migraine and inflammation [51,52]. Neurogenic inflammation is characterized by the release of vasoactive neuropeptides from nociceptive sensory nerve terminals, including calcitonin gene-related peptide (CGRP), substance P (SP), and neurokinin A. These peptides lead to the dilatation of vessels, with increased permeability and consequent exudation of fluids, plasma proteins, leukocyte extravasation, and mast cell degranulation [51]. In particular, it has been 
proposed that migraine may be associated with an inflammation of the meninges, especially the dura mater. During a migraine attack, an idiopathic activation of the trigeminal sensory afferents is thought to facilitate the nociceptive transmission to the central nervous system (CNS). Accordingly, inhibition of the dural neurogenic inflammation with molecules able to inhibit the pathways involved in the activation and sensitization of trigeminovascular neurons-at both their central and peripheral perivascular nerve endings - have been tested as potential therapeutic strategies in the treatment of migraine [51].

The main current therapy for migraine is based on triptans [53], which have been shown to attenuate the release of neuropeptides and neurogenic plasma protein extravasation. These findings provide support for the validity of using animal models of neurogenic inflammation to investigate putative etiopathogenic mechanisms in migraine.

During the interictal period (headache-free days), independent studies have demonstrated increased peripheral levels of the pro-inflammatory cytokines IL- $1 \beta$, IL-6, and TNF- $\alpha$, and of the chemokine IL-8. On the other hand, the levels of the anti-inflammatory cytokine IL-10 have been found to be either unaltered or reduced in migraine patients as compared to healthy controls. Moreover, during a migraine attack, the serum concentrations of IL- $1 \beta$, IL- 6 , IL- 8 , and TNF- $\alpha$ increase, alongside the levels of IL-10; in contrast, the type 2 cytokines IL-4 and IL-5 decrease [54]. Interestingly, migraine seems to be associated with immune-inflammatory and atopic diseases sustained by both Th1- or Th2-dominant responses, such as Inflammatory Bowel Disease and asthma [54].

Many studies have already observed that CSD induces the upregulation of several pro-inflammatory cytokines $[6,40,44,55-58]$. In the present study, we evaluated the expression of $I L-1 R N$ during CSD in a model of FMH1 by using a publicly available deep SAGE dataset. The use of whole-genome expression data has been extensively used for the identification of novel pathogenic pathways and therapeutic targets in a variety of diseases (e.g., autoimmunity [59-62], cancer [63-66], hepatic [67,68], neurodegenerative, and infectious diseases [69]).

The protein encoded by $I L-1 R N$ is a soluble factor that regulates the inflammatory response, as reported by various studies $[21,22,70,71]$. However, its role in migraine is still largely unexplored. In a previous study, significantly higher levels of $I L-1 R N, T G F-\beta 1$, and $M C P-1$ in the cerebrospinal fluid of migraine patients as compared to controls were found [72].

Unlike $I L-2, I L-4, I L-10$, and $I L-13$, the expression of $I L-1 R N$ and $I L-6$ was higher in the brains of FHM1 R192Q mutant mice than in WT mice, probably due to an alteration in $\mathrm{Ca}^{2+}$ ion channels. We can speculate that these molecules may exert a homeostatic role aimed at counteracting ongoing immunoinflammatory events. Even if the precise biological mechanisms by which IL-1RN production is increased is not known, it could be explained by an induction promoted by both IL-6 [73] and IFN- $\alpha$ [74]. Indeed, a role for the IFN pathway in migraine has been described [44]. We may speculate that compensatory mechanisms may be working constantly in migraine patients via the reciprocal regulation of pro- and anti-inflammatory factors, leading to Th1-dominant responses and the consequent effects associated with these cytokines. Moreover, we found an important increase in several members of the chemokine/chemokine receptor family in FHM1 R192Q, which could contribute to the vasodilatation and to the swelling mechanism underlying migraine and nasal congestion, which represents one of the most common symptoms [75].

The role of inflammation in migraine is further supported by the therapeutic effects of non-steroidal anti-inflammatory drugs (NSAIDs), currently recommended as the first-line medications for acute migraine attacks, as they improve both pain and breathing [76,77]. Recently, monoclonal antibodies targeting the CGRP pathway (i.e. fremanezumab, eptinezumab, and galcanezumab) have also been tested in both chronic and episodic migraine, and were shown to improve migraine-associated symptoms, quality of life, and disability, and to reduce monthly migraine days [78-81].

This study may set the basis for new therapeutic strategies for the treatment of migraine, such as anakinra [82]. Anakinra is a recombinant nonglycosylated analogue of the human IL-1RN which competitively blocks the binding of IL-1ß and IL- $1 \alpha$ to the IL-1 receptors. Anakinra was approved by the Food and Drug Administration (FDA) in 2012 for chronic infantile neurological cutaneous 
and articular syndrome (CINCA) and in 2013 by the European Medicines Agency (EMA) for all subtypes of cryopyrin-associated periodic syndrome (CAPS). In nonhuman primates, anakinra has been shown to be able to cross the blood-brain barrier in a dose-dependent manner. Therefore, a direct anti-inflammatory action in the CNS is plausible [83]. Although only marginally related to migraine, a recent prospective, open-label, long-term study in 43 patients with severe cryopyrin-associated periodic syndromes (CAPS) demonstrated that anakinra treatment significantly decreased central nervous system inflammation and headaches in pediatric patients.

\section{Conclusions}

Little is known about the etiology and physiopathogenesis of migraine, but a large body of evidence shows a relationship with inflammation. In this paper, we show the gene expression of proand anti-inflammatory cytokines in a mouse migraine model. In particular, we focus on the expression of $I L-1 R N$, which appears to be over-expressed after the CSD, suggesting a possible attempt to modulate the inflammatory response. This study may be the first one that allows a better understanding of the development of the disease and may aid in the search for new therapeutic strategies in migraine.

Supplementary Materials: The following are available online at http://www.mdpi.com/2076-3425/9/7/172/s1, File 1: Genes functionally related to IL1RN, Table S1: Multiple comparison.

Author Contributions: Conceptualization, S.D.L., E.M., F.N., P.F., M.C.P.; methodology, S.D.L., P.F., F.N.; formal analysis, S.D.L., P.F., R.N.; writing-original draft preparation, S.D.L., E.C. and M.S.B.; writing-review and editing, E.M., M.S.B., F.N., and M.C.P.; project administration, E.M., P.B., F.N.; funding acquisition, E.M., P.B., and F.N. All authors read and approved the final version of the manuscript.

Funding: This study was supported by current research funds 2018 of IRCCS Centro Neurolesi “Bonino Pulejo", Messina-Italy.

Conflicts of Interest: The authors declare no conflict of interest.

Sample Availability: Data are available from the Gene Expression Ombnibus Database.

\section{References}

1. Stovner, L.J.; Hagen, K.; Jensen, R.; Katsarava, Z.; Lipton, R.B.; Scher, A.I.; Steiner, T.J.; Zwart, J.A. The global burden of headache: A documentation of headache prevalence and disability worldwide. Cephalalgia 2007, 27, 193-210. [CrossRef] [PubMed]

2. Vetvik, K.G.; MacGregor, E.A. Sex differences in the epidemiology, clinical features, and pathophysiology of migraine. Lancet Neurol. 2017, 16, 76-87. [CrossRef]

3. Russell, M.B.; Rasmussen, B.K.; Thorvaldsen, P.; Olesen, J. Prevalence and sex-ratio of the subtypes of migraine. Int. J. Epidemiol. 1995. [CrossRef] [PubMed]

4. Headache Classification Committee of the International Headache Society (IHS). The International Classification of Headache Disorders, 3rd edition (beta version). Cephalalgia 2013. [CrossRef]

5. Lauritzen, M. Pathophysiology of the migraine aura: The spreading depression theory. Brain 1994, 117 Pt 1, 199-210. [CrossRef]

6. Cui, Y.; Kataoka, Y.; Watanabe, Y. Role of cortical spreading depression in the pathophysiology of migraine. Neurosci. Bull. 2014, 30, 812-822. [CrossRef] [PubMed]

7. Longoni, M.; Ferrarese, C. Inflammation and excitotoxicity: Role in migraine pathogenesis. Neurol. Sci. 2006. [CrossRef]

8. Edvinsson, L.; Haanes, K.A.; Warfvinge, K. Does inflammation have a role in migraine? Nat. Rev. Neurol. 2019. [CrossRef]

9. Cacabelos, R.; Torrellas, C.; Fernández-Novoa, L.; López-Muñoz, F. Histamine and Immune Biomarkers in CNS Disorders. Mediat. Inflamm. 2016, 2016, 1-10. [CrossRef]

10. Roeleveld, D.M.; Koenders, M.I. The role of the Th17 cytokines IL-17 and IL-22 in Rheumatoid Arthritis pathogenesis and developments in cytokine immunotherapy. Cytokine 2015, 74, 101-107. [CrossRef]

11. Zhang, H.-L.; Zheng, X.-Y.; Zhu, J. Th1/Th2/Th17/Treg cytokines in Guillain-Barré syndrome and experimental autoimmune neuritis. Cytokine Growth Factor Rev. 2013, 24, 443-453. [CrossRef] [PubMed] 
12. Chakraborty, S.; Kubatzky, K.F.; Mitra, D.K. An Update on Interleukin-9: From Its Cellular Source and Signal Transduction to Its Role in Immunopathogenesis. Int. J. Mol. Sci. 2019, 20, 2113. [CrossRef] [PubMed]

13. Dujmovic, I.; Mangano, K.; Pekmezovic, T.; Quattrocchi, C.; Mesaros, S.; Stojsavljevic, N.; Nicoletti, F.; Drulovic, J. The analysis of IL-1 beta and its naturally occurring inhibitors in multiple sclerosis: The elevation of IL-1 receptor antagonist and IL-1 receptor type II after steroid therapy. J. Neuroimmunol. 2009, 207, 101-106. [CrossRef] [PubMed]

14. Ayakannu, R.; Abdullah, N.A.; Radhakrishnan, A.K.; Lechimi Raj, V.; Liam, C.K. Relationship between various cytokines implicated in asthma. Hum. Immunol. 2019. [CrossRef]

15. Nicoletti, F.; Mancuso, G.; Cusumano, V.; Di Marco, R.; Zaccone, P.; Bendtzen, K.; Teti, G. Prevention of endotoxin-induced lethality in neonatal mice by interleukin-13. Eur. J. Immunol. 1997, 27, 1580-1583. [CrossRef] [PubMed]

16. Conway, T.F.; Hammer, L.; Furtado, S.; Mathiowitz, E.; Nicoletti, F.; Mangano, K.; Egilmez, N.K.; Auci, D.L. Oral Delivery of Particulate Transforming Growth Factor Beta 1 and All-Trans Retinoic Acid Reduces Gut Inflammation in Murine Models of Inflammatory Bowel Disease. J. Crohn's Colitis 2015, 9, 647-658. [CrossRef]

17. Nicoletti, F.; Di Marco, R.; Patti, F.; Reggio, E.; Nicoletti, A.; Zaccone, P.; Stivala, F.; Meroni, P.L.; Reggio, A. Blood levels of transforming growth factor-beta 1 (TGF-beta1) are elevated in both relapsing remitting and chronic progressive multiple sclerosis (MS) patients and are further augmented by treatment with interferon-beta 1b (IFN-beta1b). Clin. Exp. Immunol. 1998, 113, 96-99. [CrossRef]

18. Barcellini, W.; Rizzardi, G.P.; Borghi, M.O.; Nicoletti, F.; Fain, C.; Del Papa, N.; Meroni, P.L. In vitro type-1 and type-2 cytokine production in systemic lupus erythematosus: Lack of relationship with clinical disease activity. Lupus 1996, 5, 139-145. [CrossRef]

19. Fiotti, N.; Giansante, C.; Ponte, E.; Delbello, C.; Calabrese, S.; Zacchi, T.; Dobrina, A.; Guarnieri, G. Atherosclerosis and inflammation. Patterns of cytokine regulation in patients with peripheral arterial disease. Atherosclerosis 1999, 145, 51-60. [CrossRef]

20. Nielsen, C.H.; Bendtzen, K. Immunoregulation by Naturally Occurring and Disease-Associated Autoantibodies: Binding to cytokines and their role in regulation of T-cell responses. Adv. Exp. Med. Biol. 2012, 750, 116-132. [CrossRef]

21. Arend, W.P.; Malyak, M.; Guthridge, C.J.; Gabay, C. INTERLEUKIN-1 RECEPTOR ANTAGONIST: Role in Biology. Annu. Rev. Immunol. 2002. [CrossRef]

22. Nicoletti, F.; Patti, F.; Di Marco, R.; Zaccone, P.; Nicoletti, A.; Meroni, P.L.; Reggio, A. Circulating serum levels of IL-1ra in patients with relapsing remitting multiple sclerosis are normal during remission phases but significantly increased either during exacerbations or in response to IFN- $\beta$ treatment. Cytokine 1996. [CrossRef]

23. Perini, F.; D’Andrea, G.; Galloni, E.; Pignatelli, F.; Billo, G.; Alba, S.; Bussone, G.; Toso, V. Plasma cytokine levels in migraineurs and controls. Headache 2005. [CrossRef] [PubMed]

24. Empl, M.; Sostak, P.; Riedel, M.; Schwarz, M.; Müller, N.; Förderreuther, S.; Straube, A. Decreased sTNF-RI in migraine patients? Cephalalgia 2003. [CrossRef]

25. Covelli, V.; Munno, I.; Pellegrino, N.M.; Di Venere, A.; Jirillo, E.; Buscaino, G.A. Exaggerated spontaneous release of tumor necrosis factor-alpha/cachectin in patients with migraine without aura. Acta Neurol. (Napoli) 1990, 12, 257-263.

26. Yilmaz, I.A.; Özge, A.; Erdal, M.E.; Edgünlü, T.G.; Çakmak, S.E.; Yalin, O.Ö. Cytokine polymorphism in patients with migraine: Some suggestive clues of migraine and inflammation. Pain Med. 2010. [CrossRef] [PubMed]

27. Skaper, S.D. Nerve growth factor: A neuroimmune crosstalk mediator for all seasons. Immunology 2017, 151, 1-15. [CrossRef] [PubMed]

28. Moskowitz, M.A. Neurogenic inflammation in the pathophysiology and treatment of migraine. Neurology 1993, 43 (Suppl. S3), S16-S20. [PubMed]

29. Waeber, C.; Moskowitz, M.A. Migraine as an inflammatory disorder. Neurology 2012. [CrossRef]

30. Vecchia, D.; Pietrobon, D. Migraine: A disorder of brain excitatory-inhibitory balance? Trends Neurosci. 2012, 35, 507-520. [CrossRef] 
31. Ceruti, S.; Villa, G.; Fumagalli, M.; Colombo, L.; Magni, G.; Zanardelli, M.; Fabbretti, E.; Verderio, C.; van den Maagdenberg, A.M.J.M.; Nistri, A.; et al. Calcitonin Gene-Related Peptide-Mediated Enhancement of Purinergic Neuron/Glia Communication by the Algogenic Factor Bradykinin in Mouse Trigeminal Ganglia from Wild-Type and R192Q Cav2.1 Knock-In Mice: Implications for Basic Mechanisms of Migraine Pain. J. Neurosci. 2011. [CrossRef]

32. Friedman, M.H. Local inflammation as a mediator of migraine and tension-type headache. Headache 2004. [CrossRef]

33. Rowe, B.H.; Colman, I.; Edmonds, M.L.; Blitz, S.; Walker, A.; Wiens, S. Randomized controlled trial of intravenous dexamethasone to prevent relapse in acute migraine headache. Headache 2008. [CrossRef]

34. Van Den Maagdenberg, A.M.J.M.; Haan, J.; Terwindt, G.M.; Ferrari, M.D. Migraine: Gene mutations and functional consequences. Curr. Opin. Neurol. 2007, 20, 299-305. [CrossRef]

35. Ophoff, R.A.; Terwindt, G.M.; Vergouwe, M.N.; Van Eijk, R.; Oefner, P.J.; Hoffman, S.M.G.; Lamerdin, J.E.; Mohrenweiser, H.W.; Bulman, D.E.; Ferrari, M.; et al. Familial hemiplegic migraine and episodic ataxia type-2 are caused by mutations in the Ca2+ channel gene CACNL1A4. Cell 1996. [CrossRef]

36. Van Den Maagdenberg, A.M.J.M.; Pietrobon, D.; Pizzorusso, T.; Kaja, S.; Broos, L.A.M.; Cesetti, T.; Van De Ven, R.C.G.; Tottene, A.; Van Der Kaa, J.; Plomp, J.J.; et al. A Cacna1a knockin migraine mouse model with increased susceptibility to cortical spreading depression. Neuron 2004. [CrossRef]

37. Jurkat-Rott, K.; Lerche, H.; Weber, Y.; Lehmann-Horn, F. Hereditary channelopathies in neurology. Adv. Exp. Med. Biol. 2010, 686, 305-334.

38. Tfelt-Hansen, P.C.; Koehler, P.J. One hundred years of migraine research: Major clinical and scientific observations from 1910 to 2010. Headache 2011, 51, 752-778. [CrossRef]

39. Tottene, A.; Conti, R.; Fabbro, A.; Vecchia, D.; Shapovalova, M.; Santello, M.; van den Maagdenberg, A.M.J.M.; Ferrari, M.D.; Pietrobon, D. Enhanced Excitatory Transmission at Cortical Synapses as the Basis for Facilitated Spreading Depression in CaV2.1 Knockin Migraine Mice. Neuron 2009. [CrossRef]

40. Karatas, H.; Erdener, S.E.; Gursoy-Ozdemir, Y.; Lule, S.; Eren-Koçak, E.; Sen, Z.D.; Dalkara, T. Spreading depression triggers headache by activating neuronal Panx1 channels. Science 2013, 339, 1092-1095. [CrossRef]

41. Noseda, R.; Burstein, R. Migraine pathophysiology: Anatomy of the trigeminovascular pathway and associated neurological symptoms, cortical spreading depression, sensitization, and modulation of pain. Pain 2013, 154 (Suppl. S1), S44-S53. [CrossRef]

42. Zhang, X.; Levy, D.; Kainz, V.; Noseda, R.; Jakubowski, M.; Burstein, R. Activation of central trigeminovascular neurons by cortical spreading depression. Ann. Neurol. 2011. [CrossRef]

43. GEO DataSets. Available online: https://www.ncbi.nlm.nih.gov/gds (accessed on 15 April 2019).

44. Eising, E.; Shyti, R.; 't Hoen, P.A.C.; Vijfhuizen, L.S.; Huisman, S.M.H.; Broos, L.A.M.; Mahfouz, A.; Reinders, M.J.T.; Ferrari, M.D.; Tolner, E.A.; et al. Cortical Spreading Depression Causes Unique Dysregulation of Inflammatory Pathways in a Transgenic Mouse Model of Migraine. Mol. Neurobiol. 2017. [CrossRef]

45. STRING. Available online: https://string-db.org/ (accessed on 15 April 2019).

46. Heatmapper. Available online: http://www.heatmapper.ca/ (accessed on 15 April 2019).

47. CoExpress software. Available online: http://www.bioinformatics.lu/coexpress/ (accessed on 15 April 2019).

48. DAVID version 6.8. Available online: http://david.abcc.ncifcrf.gov/ (accessed on 15 April 2019).

49. IBM SPSS Statistics 23. Available online: https://www.spss.it/ (accessed on 15 April 2019).

50. GraphPad Prism 8.0.2. Available online: https://www.graphpad.com/ (accessed on 15 April 2019).

51. Malhotra, R. Understanding migraine: Potential role of neurogenic inflammation. Ann. Indian Acad. Neurol. 2016. [CrossRef]

52. Ramachandran, R. Neurogenic inflammation and its role in migraine. Semin. Immunopathol. 2018, 40, 301-314. [CrossRef]

53. Johnston, M.M.; Rapoport, A.M. Triptans for the management of migraine. Drugs 2010, 70, 1505-1518. [CrossRef]

54. Oliveira, A.B.; Bachi, A.L.L.; Ribeiro, R.T.; Mello, M.T.; Tufik, S.; Peres, M.F.P. Unbalanced plasma TNF- $\alpha$ and IL-12/IL-10 profile in women with migraine is associated with psychological and physiological outcomes. J. Neuroimmunol. 2017, 313, 138-144. [CrossRef]

55. Costa, C.; Tozzi, A.; Rainero, I.; Cupini, L.M.; Calabresi, P.; Ayata, C.; Sarchielli, P. Cortical spreading depression as a target for anti-migraine agents. J. Headache Pain 2013. [CrossRef] 
56. Thompson, C.S.; Hakim, A.M. Cortical Spreading Depression Modifies Components of the Inflammatory Cascade. Mol. Neurobiol. 2005. [CrossRef]

57. Choudhuri, R.; Cui, L.; Yong, C.; Bowyer, S.; Klein, R.M.; Welch, K.M.A.; Berman, N.E.J. Cortical spreading depression and gene regulation: Relevance to migraine. Ann. Neurol. 2002. [CrossRef]

58. Urbach, A.; Bruehl, C.; Witte, O.W. Microarray-based long-term detection of genes differentially expressed after cortical spreading depression. Eur. J. Neurosci. 2006. [CrossRef]

59. Fagone, P.; Mazzon, E.; Cavalli, E.; Bramanti, A.; Petralia, M.C.; Mangano, K.; Al-Abed, Y.; Bramati, P.; Nicoletti, F. Contribution of the macrophage migration inhibitory factor superfamily of cytokines in the pathogenesis of preclinical and human multiple sclerosis: In silico and in vivo evidences. J. Neuroimmunol. 2018, 322. [CrossRef]

60. Fagone, P.; Mazzon, E.; Mammana, S.; Di Marco, R.; Spinasanta, F.; Basile, M.S.; Petralia, M.C.; Bramanti, P.; Nicoletti, F.; Mangano, K. Identification of CD4+ T cell biomarkers for predicting the response of patients with relapsing-remitting multiple sclerosis to natalizumab treatment. Mol. Med. Rep. 2019, 20, 678-684. [CrossRef]

61. Mammana, S.; Bramanti, P.; Mazzon, E.; Cavalli, E.; Basile, M.S.; Fagone, P.; Petralia, M.C.; McCubrey, J.A.; Nicoletti, F.; Mangano, K. Preclinical evaluation of the PI3K/Akt/mTOR pathway in animal models of multiple sclerosis. Oncotarget 2018, 9, 8263-8277. [CrossRef]

62. Fagone, P.; Muthumani, K.; Mangano, K.; Magro, G.; Meroni, P.L.; Kim, J.J.; Sardesai, N.Y.; Weiner, D.B.; Nicoletti, F. VGX-1027 modulates genes involved in lipopolysaccharide-induced Toll-like receptor 4 activation and in a murine model of systemic lupus erythematosus. Immunology 2014, 142. [CrossRef]

63. Presti, M.; Mazzon, E.; Basile, M.S.; Petralia, M.C.; Bramanti, A.; Colletti, G.; Bramanti, P.; Nicoletti, F.; Fagone, P. Overexpression of macrophage migration inhibitory factor and functionally-related genes, D-DT, CD74, CD44, CXCR2 and CXCR4, in glioblastoma. Oncol. Lett. 2018, 16, 2881-2886. [CrossRef]

64. Fagone, P.; Caltabiano, R.; Russo, A.; Lupo, G.; Anfuso, C.D.; Basile, M.S.; Longo, A.; Nicoletti, F.; De Pasquale, R.; Libra, M.; et al. Identification of novel chemotherapeutic strategies for metastatic uveal melanoma. Sci. Rep. 2017, 7, 44564. [CrossRef]

65. Basile, M.S.; Mazzon, E.; Russo, A.; Mammana, S.; Longo, A.; Bonfiglio, V.; Fallico, M.; Caltabiano, R.; Fagone, P.; Nicoletti, F.; et al. Differential modulation and prognostic values of immune-escape genes in uveal melanoma. PLoS ONE 2019, 14, e0210276. [CrossRef]

66. Mangano, K.; Mazzon, E.; Basile, M.S.; Di Marco, R.; Bramanti, P.; Mammana, S.; Petralia, M.C.; Fagone, P.; Nicoletti, F. Pathogenic role for macrophage migration inhibitory factor in glioblastoma and its targeting with specific inhibitors as novel tailored therapeutic approach. Oncotarget 2018, 9, 17951-17970. [CrossRef]

67. Fagone, P.; Mangano, K.; Mammana, S.; Pesce, A.; Pesce, A.; Caltabiano, R.; Giorlandino, A.; Portale, T.R.; Cavalli, E.; Lombardo, G.A.G.; et al. Identification of novel targets for the diagnosis and treatment of liver fibrosis. Int. J. Mol. Med. 2015, 36, 747-752. [CrossRef]

68. Mangano, K.; Cavalli, E.; Mammana, S.; Basile, M.S.; Caltabiano, R.; Pesce, A.; Puleo, S.; Atanasov, A.G.; Magro, G.; Nicoletti, F.; et al. Involvement of the Nrf2/HO-1/CO axis and therapeutic intervention with the CO-releasing molecule CORM-A1, in a murine model of autoimmune hepatitis. J. Cell. Physiol. 2018, 233, 4156-4165. [CrossRef]

69. Fagone, P.; Nunnari, G.; Lazzara, F.; Longo, A.; Cambria, D.; Distefano, G.; Palumbo, M.; Nicoletti, F.; Malaguarnera, L.; Di Rosa, M. Induction of OAS gene family in HIV monocyte infected patients with high and low viral load. Antivir. Res. 2016, 131. [CrossRef]

70. Arend, W.P.; Gabay, C. Physiologic role of interleukin-1 receptor antagonist. Arthritis Res. 2000, 2, $245-248$. [CrossRef]

71. Freeman, B.D.; Buchman, T.G. Interleukin-1 receptor antagonist as therapy for inflammatory disorders. Expert Opin. Biol. 2005. [CrossRef]

72. Bø, S.H.; Davidsen, E.M.; Gulbrandsen, P.; Dietrichs, E.; Bovim, G.; Stovner, L.J.; White, L.R. Cerebrospinal fluid cytokine levels in migraine, tension-type headache and cervicogenic headache. Cephalalgia 2009. [CrossRef]

73. Tilg, H.; Trehu, E.; Atkins, M.B.; Dinarello, C.A.; Mier, J.W. Interleukin-6 (IL-6) as an anti-inflammatory cytokine: Induction of circulating IL-1 receptor antagonist and soluble tumor necrosis factor receptor p55. Blood 1994, 83, 113-118. 
74. Tilg, H.; Mier, J.W.; Vogel, W.; Aulitzky, W.E.; Wiedermann, C.J.; Vannier, E.; Huber, C.; Dinarello, C.A. Induction of circulating IL-1 receptor antagonist by IFN treatment. J. Immunol. 1993, 150, 4678-4692.

75. Arslan, H.H.; Tokgöz, E.; Yildizolu, Ü.; Durmaz, A.; Bek, S.; Gerek, M. Evaluation of the changes in the nasal cavity during the migraine attack. J. Craniofac. Surg. 2014. [CrossRef]

76. Aukerman, G.; Knutson, D.; Miser, W.F. Management of the acute migraine headache. Am. Fam. Physician 2002, 66, 2123-2130.

77. Hsu, Y.C.; Lin, K.C.; Wang, S.J.; Wang, P.J.; Wang, Y.F.; Lee, L.H.; Wu, Z.A.; Shih, C.S.; Chen, Y.Y.; Chen, W.H.; et al. Medical treatment guidelines for acute migraine attacks. Acta Neurol. Taiwan. 2017, 26, 78-96.

78. Raffaelli, B.; Mussetto, V.; Israel, H.; Neeb, L.; Reuter, U. Erenumab and galcanezumab in chronic migraine prevention: Effects after treatment termination. J. Headache Pain 2019, 20, 66. [CrossRef]

79. Silberstein, S.D.; Stauffer, V.L.; Day, K.A.; Lipsius, S.; Wilson, M.-C. Galcanezumab in episodic migraine: Subgroup analyses of efficacy by high versus low frequency of migraine headaches in phase 3 studies (EVOLVE-1 \& EVOLVE-2). J. Headache Pain 2019, 20, 75. [CrossRef]

80. Dodick, D.W.; Lipton, R.B.; Silberstein, S.; Goadsby, P.J.; Biondi, D.; Hirman, J.; Cady, R.; Smith, J. Eptinezumab for prevention of chronic migraine: A randomized phase $2 \mathrm{~b}$ clinical trial. Cephalalgia 2019. [CrossRef]

81. Silberstein, S.D.; Cohen, J.M.; Yeung, P.P. Fremanezumab for the preventive treatment of migraine. Expert Opin. Biol. 2019, 1-9. [CrossRef]

82. Neven, B.; Marvillet, I.; Terrada, C.; Ferster, A.; Boddaert, N.; Couloignier, V.; Pinto, G.; Pagnier, A.; Bodemer, C.; Tardieu, M.; et al. Long-term efficacy of the interleukin-1 receptor antagonist anakinra in ten patients with neonatal-onset multisystem inflammatory disease/chronic infantile neurologic, cutaneous, articular syndrome. Arthritis Rheum. 2010. [CrossRef]

83. Landmann, E.C.; Walker, U.A. Pharmacological treatment options for cryopyrin-associated periodic syndromes. Expert Rev. Clin. Pharm. 2017, 10, 855-864. [CrossRef]

(C) 2019 by the authors. Licensee MDPI, Basel, Switzerland. This article is an open access article distributed under the terms and conditions of the Creative Commons Attribution (CC BY) license (http://creativecommons.org/licenses/by/4.0/). 